\title{
Aortic root anatomy as a factor in the fluid mechanics of transcatheter aortic valve replacement
}

\author{
Muralidhar Padala, PhD
}

\footnotetext{
From the Structural Heart Research \& Innovation Laboratory, Carlyle Fraser Heart Center, Emory University Hospital Midtown, Atlanta, Ga; and Division of Cardiothoracic Surgery, Joseph P. Whitehead Department of Surgery, Emory University, Atlanta, Ga.

Disclosures: Dr Padala is a consultant for Heart Repair Technologies Inc, and has received honorarium for presenting valve disease research models to the Edwards Lifesciences Advanced Technology Group.

Received for publication Oct 17, 2018; accepted for publication Oct 18, 2018; available ahead of print Dec 6, 2018.

Address for reprints: Muralidhar Padala, PhD, Division of Cardiothoracic Surgery, Joseph P. Whitehead Department of Surgery, Emory University, 380B Northyards Blvd, Atlanta, GA 30033 (E-mail: spadala@emory.edu).

J Thorac Cardiovasc Surg 2019;157:550-1

$0022-5223 / \$ 36.00$

Copyright (c) 2018 by The American Association for Thoracic Surgery

https://doi.org/10.1016/j.jtcvs.2018.10.093
}

The aortic root is a dynamic structure ${ }^{1}$ that consists of the aortoventricular junction at its proximal end, a crownshaped fibrous aortic root from which the 3 aortic valve leaflets emerge and are constrained, 3 bulging sinuses of Valsalva that emerge from the aortoventricular junction and terminate in the tubular ascending aorta at the sinotubular junction, and 2 of the sinuses housing the coronary ostia. $^{2-4}$ During the cardiac cycle, the aortic root undergoes dynamic volumetric changes, with early expansion in the isovolumetric relaxation phase that peaks within the first third of ejection, followed by a slow and then rapid reduction in root volume until late diastole. These volumetric changes vary from the proximal to distal end of the root, with the proximal end motion governed possibly by the subaortic myocardial contractility and the distal end motion dependent upon the aortic tissue material properties and aortic pressure. The functional consequence of this dynamism is not fully understood, but it is hypothesized that these motions aid in favorable aortic valve leaflet opening and closure and sinus flow dynamics that enable aortic valve closure and coronary artery filling. In diseases involving aortic root dilatation, loss of native root dynamics and change in root geometry are known to impair both aortic valve and coronary artery flow. ${ }^{5}$ On the contrary, in aortic valve stenosis where the root dynamics and geometry may be preserved but ejection through the aortic valve is altered, the blood flow mechanics may alter the aortic dynamics. The physiologic basis for aortic root dynamics and the finesse with which structure drives function remains of much interest to surgeons who seek to restore these geometries and dynamics in patients with diseases affecting the aortic root. Although it seems tempting to ignore these subtle dynamics, data from the Ross operation registry demonstrates that preserving these dynamics may enhance valve function and durability.

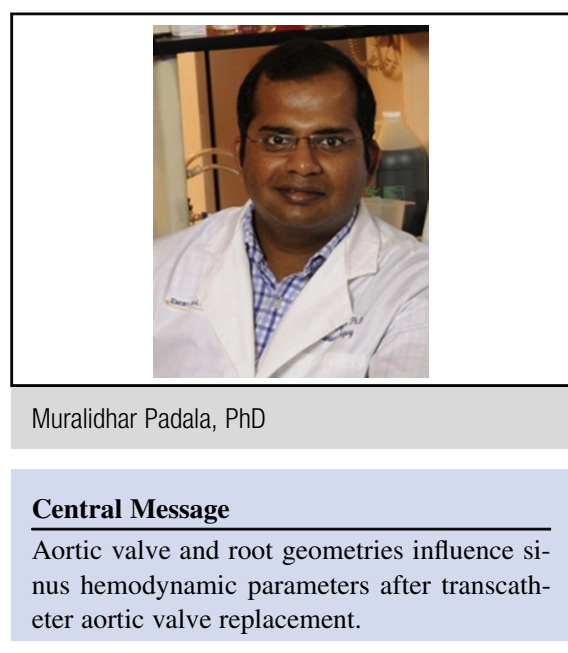

See Article page 540
In transcatheter aortic valve replacement (TAVR), the stenotic aortic valve is dilated with a balloon and metallic replacement stent with prosthetic leaflets is implanted into the native calcified valve to resolve the valve stenosis. The metallic stent of the TAVR valve imposes a radially outward force on the aortoventricular junction and the aortic annulus for attachment, displaces the native leaflets with their calcific nodules into the sinuses of Valsalva, and some types of TAVR valves extend to the sinotubular junction and radially expand onto it. It is likely that implantation of a TAVR valve into an aortic root may alter or inhibit some or all the native mechanics and dynamism, which may have unintended consequences. ${ }^{6}$ For instance, the TAVR valve compartmentalizes the aortic sinuses into the native sinus volume between the immobile calcified native leaflet and the native sinus wall, and an artificial sinus volume between the ventricular surface of the immobilized native leaflet and the prosthetic leaflet of the TAVR valve. These new volumes formed in the aortic root could induce abnormal blood flow, and may explain the clinical observation of thrombus formation on TAVR valves. ${ }^{7,8}$ As use of TAVR valves continues to grow, other clinical complications may be revealed that require engineering and physiological studies to fathom and possible inhibit.

Hatoum and colleagues ${ }^{9}$ report their observations on flow stasis in the aortic sinuses using the Sapien (Edwards Lifesciences, Irvine, Calif) and Corevalve (Medtronic, Minneapolis, Minn) valve products in aortic root geometries 
from a stenotic bicuspid and a tricuspid aortic valve. Native aortic root and valve leaflets were segmented from patient images, 3-dimensional structures were reconstructed and then printed using materials of different stiffness for the soft tissue and the calcific nodules, and particle image velocimetry was used to experimentally measure the velocities and calculate sinus vorticity, shear stress dynamics, and sinus washout. These measurements and calculations were performed in both valve and root geometries using 2 sizes of the Sapien and Corevalve valve products. The first result is that the systolic ejection jet velocities and the resulting sinus vorticity were higher with the Sapien valve than the Corevalve in both models. The trends were similar in mid-diastole as well. The second result is that both valves performed better in model 2, which is the tricuspid aortic valve. The third result-probably the most interesting - is that blood and particles washed out of the aortic sinuses differently when the Sapien and Corevalve products were used in bicuspid and tricuspid valves. In bicuspid valve geometry, approximately 3.5 cardiac cycles were required for all blood entering the sinus to wash out with the Corevalve, but such washout occurred within 1.25 cardiac cycles with the Sapien valve. In the tricuspid geometry, even after 10 cardiac cycles, approximately $20 \%$ of particles did not washout with the Corevalve, whereas all particles washed out after 7.5 cardiac cycles with the Sapien valve. These results indicate that sinus flow dynamics depend on the type of valve chosen and its design features, and potentially on the anatomy of the valve, if not the root.

Hatoum and colleagues ${ }^{9}$ should be congratulated for this detailed effort, but the results must be read with the limitations of the experimental technique in mind. Aortic root dynamism or native coronary artery filling and emptying are lacking in bench top models, which limit their application to clinical situations. Refinement of such models, and investigating the influence of cardiac dynamics, heart rate, aortic root geometry, sinus geometry, and blood viscosity on sinus flow dynamics may be considered for future studies.

\section{References}

1. Mori S, Anderson RH, Tahara N, Izawa Y, Toba T, Fujiwara S, et al. The differences between bisecting and off-center cuts of the aortic root: the three-dimensional anatomy of the aortic root reconstructed from the living heart. Echocardiography. 2017;34:453-61.

2. Schoenhoff FS, Loupatatzis C, Immer FF, Stoupis C, Carrel TP, Eckstein FS The role of the sinuses of Valsalva in aortic root flow dynamics and aortic root surgery: evaluation by magnetic resonance imaging. J Heart Valve Dis. 2009; $18: 380-5$

3. Lansac E, Lim HS, Shomura Y, Lim KH, Rice NT, Goetz WA, et al. Aortic root dynamics are asymmetric. J Heart Valve Dis. 2005;14:400-7.

4. Dagum P, Green GR, Nistal FJ, Daughters GT, Timek TA, Foppiano LE, et al Deformational dynamics of the aortic root: modes and physiologic determinants. Circulation. 1999;100:II54-62.

5. Querzoli G, Fortini S, Espa S, Costantini M, Sorgini F. Fluid dynamics of aortic root dilation in Marfan syndrome. J Biomech. 2014;47:3120-8.

6. Guyton RA, Padala M. Transcatheter aortic valve replacement in bicuspid aortic stenosis: early success but concerning red flags. JACC Cardiovasc Interv. 2016 9:825-7.

7. Sondergaard L, De Backer O, Kofoed KF, Jilaihawi H, Fuchs A, Chakravarty T, et al. Natural history of subclinical leaflet thrombosis affecting motion in bioprosthetic aortic valves. Eur Heart J. 2017;38:2201-7.

8. Chakravarty T, Sondergaard L, Friedman J, De Backer O, Berman D, Kofoed KF et al. Subclinical leaflet thrombosis in surgical and transcatheter bioprosthetic aortic valves: an observational study. Lancet. 2017;389:2383-92.

9. Hatoum H, Dollery J, Lilly SM, Crestanello J, Dasi LP. Impact of patient-specific morphologies on sinus flow stasis in transcatheter aortic valve replacement: an in vitro study. J Thorac Cardiovasc Surg. 2019; 157:540-9. 